\title{
Investigation on Boronizing of N80 Tube Steel
}

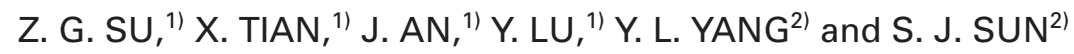 \\ 1) Key Laboratory of Automobile Materials, Ministry of Education, Department of Materials Science and Engineering, Nanling \\ Campus of Jilin University, Changchun 130025, Peoples' Republic of China. E-mail: anjian@jlu.edu.cn \\ 2) Songyuan Daduo Oilfield Accessory Industry Co. Ltd., Songyuan, 138000, Peoples' Republic of China.
}

(Received on May 26, 2009; accepted on July 21, 2009)

\begin{abstract}
In present paper, boronizing was applied to N80 steel tube by pack boronizing, and its effect on mechanical properties, wear and corrosion of N80 tube steel was investigated. A dual-phase boride layer composed of $\mathrm{FeB}$ and $\mathrm{F}_{2} \mathrm{~B}$ phases was formed on the surface of the steel substrate in a hardness range of 1220-1340 HV. A set-up was designed to reduce usage of the boriding agent and accelerate the pipe's cooling process after boronizing treatment. In order to meet the tensile properties of N80 steel required by API SPEC 5L, different cooling methods were employed including annealing, normalizing, fan-cooling and graphite-bar assisted rapid cooling. Among these methods, graphite-bar assisted rapid cooling resulted in the highest amount of pearlite in the steel substrate and the highest mechanical properties, satisfying the mechanical properties of API SPEC 5L. The boronized N80 steel exhibited an abrasive wear mechanism and showed a higher wear resistance under a given sliding condition due to the great hardness and integrity of the boride layer, and it also displayed an excellent corrosion resistance in both $\mathrm{H}_{2} \mathrm{SO}_{4}$ and $\mathrm{HCl}$ acid environments.
\end{abstract}

KEY WORDS: boronizing; mechanical properties; wear; corrosion.

\section{Introduction}

Boronizing is one of the thermochemical surface treatments widely used in the industry. This is a technique by thermodiffusion followed by chemical reaction at the surface. The boride layer improves strongly the surface hardness (about 1200-2000 HV), wear resistance and anticorrosion properties. ${ }^{1)}$ This treatment is generally performed between 1123 and $1323 \mathrm{~K}$ for $2-10 \mathrm{~h}$ and it is frequently performed by pack boronizing, a process similar to pack carburizing. The pack usually contains a source of boron, usually boron carbide $\left(\mathrm{B}_{4} \mathrm{C}\right)$, an activator (usually $\left.\mathrm{KBF}_{4}\right)$ to deposit atomic boron at the workpiece and a diluent ( $\mathrm{SiC}$ or $\mathrm{Al}_{2} \mathrm{O}_{3}$ ). Pack boronizing involves placing a component in the powder mixture, sealing it in a container and heating the container up to the required temperature for the required period of time and cooling in the furnace or in the air. Boronizing of carbon steels usually leads to the formation of two different iron boride phases: FeB at the surface and $\mathrm{Fe}_{2} \mathrm{~B}$ between the matrix and FeB. The morphology, growth and phase composition of the boride layer are influenced by the alloying elements in the base material. ${ }^{2)}$ Industrial boronizing can be carried out on most ferrous materials such as structural steels, cast steels, armco irons, gray and ductile irons. Some of the researchers have reported the effects of conventional heat treatment and boronizing applied to SAE 1010 and SAE 1040 structural steels, D2 tool steel, ductile iron, 304 stainless steel and 5115 steel. $^{3-5)}$ In their investigation, carburization, nitriding, transformation hardening and boronizing applied to the specimens were exam- ined in terms of layer thickness, corrosion and wear resistance. Boronized steels consistently outperform nitrided and carburized steels, because the iron boride formed at the surface exhibited substantially higher hardness ( $\mathrm{HV}=$ 1200-2 000) as compared to carburized or nitrided steels $(\mathrm{HV}=650-900)$. In particular, boronized steels exhibited excellent resistance to a variety of tribological wear mechanisms. ${ }^{6)}$ In addition, the resistance of boronized steels against the attack by non-oxidizing dilute acids, alkalis and molten metals was also outstanding.

The corrosion and wear of tube products are very serious in oil and gas wells under complex service conditions such as high temperature, high pressure, multiphase, $\mathrm{pH}$ value, ion concentrations and partial-wear between the tube and sucker rod, and may result in tube rupture or leak, which can be catastrophic and cause significant economic and environmental damages. A relatively inexpensive material widely used for tube in oilfield is N80 steel, but according to the investigation on degradation of the tubing metal in hydrogen-sulfide environments by Radkevych and Zavyalov, ${ }^{7,8)}$ it displayed unsatisfied performance under severe conditions of high corrosion and heavy wear environments, especially in acid environment containing $\mathrm{CO}_{2}$ and $\mathrm{H}_{2} \mathrm{~S}$. To improve the wear and corrosion properties of tube, various surface techniques have been employed including nitriding, electroless $\mathrm{Ni}-\mathrm{P}$ coatings and hard $\mathrm{Cr}$ coatings. Martini et $a l .{ }^{9)}$ reported the wear behavior of the boride coating thermochemically grown on an iron and a medium carbon steel by pack boronizing, in comparison with other surface modifications, such as nitriding, hard chromium coatings and 
WC-Co coatings. The wear resistance of boride coating was intermediate between nitrided steel surface and WC-Co coating, and comparable to the hard chromium coating. The boronized AISI H13 hot work steel showed a better corrosion resistance in $\mathrm{H}_{2} \mathrm{SO}_{4}$ and $\mathrm{H}_{3} \mathrm{PO}_{4}$ environments in the investigation conducted by Kariofillis et al. ${ }^{10)}$ Therefore, boronizing is expected to also improve effectively the corrosion and wear resistance of N80 steel tube. However, to ensure that the boronizing of N80 tube steel shall be practical in oil industry, a few problems associated with the process must be addressed. Firstly, the usage of boriding agent should be minimized, because a quite amount of boriding agent is required to fill the interior of the tubes, which are usually about 9-10 $\mathrm{m}$ long, thus, the high cost of boriding agent must be controlled within a acceptable range. Secondly, an appropriate cooling method must be chosen to ensure that the tube shall meet the mechanical properties demanded by API SPEC 5L. Because the boronized workpieces usually are cooled in the furnace or in the air, the powder mixture within the tube interior makes the cooling rate so slow that it is difficult for the tube to meet the mechanical properties required by API SPEC 5L.

The main aim of this study is to make an attempt at boronizing of N80 steel using a reduced amount pack powder and choosing an appropriate cooling method which satisfies the mechanical properties required by API SPEC 5L, meanwhile the effects of boride layer and cooling rate on tensile properties are examined. The effects of boronizing on the wear and corrosion rates are also presented. The results can provide a useful reference on extending application of boronizing into oil industry.

\section{Experimental Details}

Boronizing process was carried out at $1133 \mathrm{~K}$ for $5 \mathrm{~h}$ with a powder mixture consisted of $\mathrm{B}_{4} \mathrm{C}(5 \mathrm{wt} \%), \mathrm{KBF}_{4}$ $(5 \mathrm{wt} \%)$, a reducing agent $(\mathrm{Mn}-\mathrm{Fe}, 10 \mathrm{wt} \%)$ and $\mathrm{SiC}$ (balance) in an electrical resistance furnace. Four pieces of pipe $160 \mathrm{~mm}$ long were cut from a N80 steel oil pipe with $73.02 \mathrm{~mm}$ outer diameter and $5.51 \mathrm{~mm}$ wall thickness. The chemical composition of N80 steel is given in Table 1. Different cooling methods and interior design of the boronizing set-up were used to obtain different cooling velocities. The schematics of the boronized pipes in the experimental set up were shown in Fig. 1. A graphite bar with a diameter of $33 \mathrm{~mm}$ was placed in the center of boriding agent to reduce the usage of boriding agent and increase the cooling velocity, for graphite has lower specific heat than incompact boriding agent. The distance between the edge of graphite bar and the inner surface of the pipe is $14.5 \mathrm{~mm}$ ( $>10 \mathrm{~mm})$, therefore, no negative effect could be exerted on the microstructure, composition and thickness of the boride layer as pointed out by Jain and Sundararajan in their investigation on the influence of the pack thickness of the boronizing mixture on the boriding of steel. ${ }^{11)}$ Four different cooling methods were applied, namely, annealing, normalizing, fan cooling and fan cooling with the graphite bar immersed in the center of the boriding agent (graphite-bar assisted rapid cooling), thus different cooling velocities could be obtained, correspondingly microstructure of the steel substrate
Table 1. Chemical composition of N80 steel.

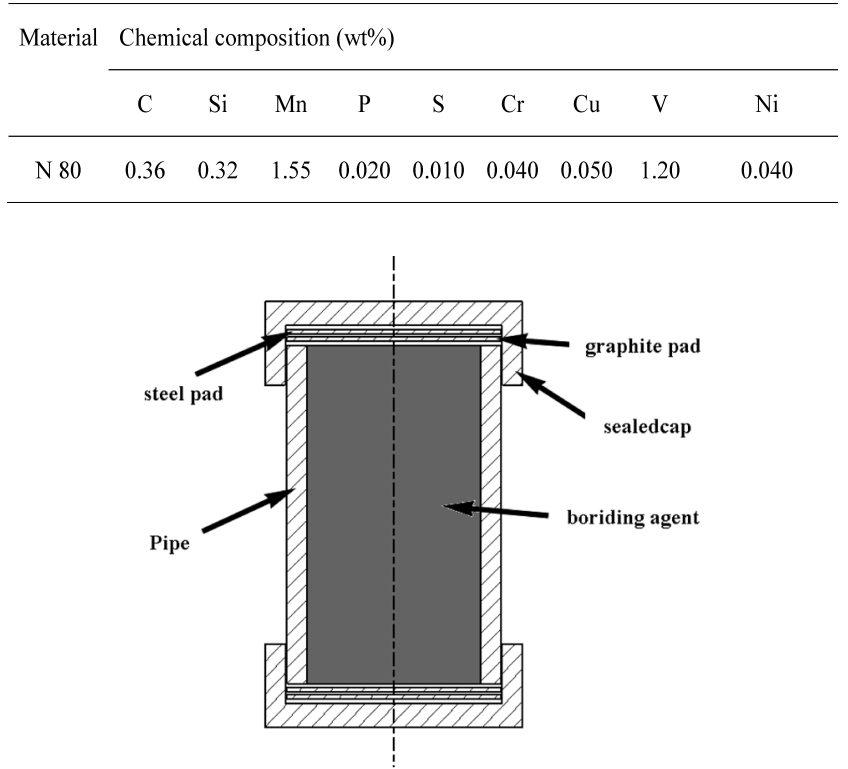

(a)

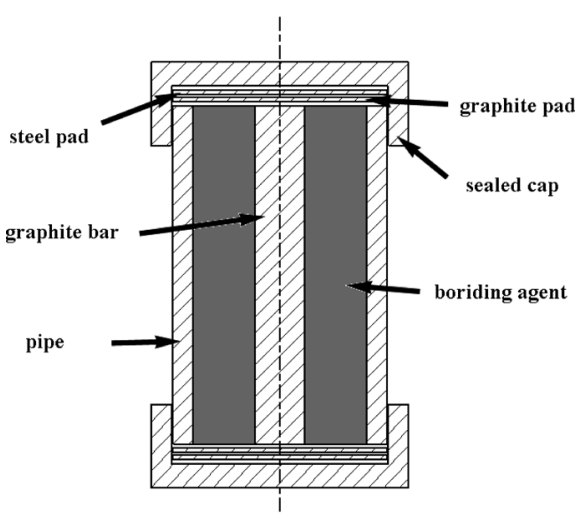

(b)

Fig. 1. Schematic representation of the set-up used to boronize pipes: (a) without graphite bar, (b) with a graphite bar in the center of boriding agent.

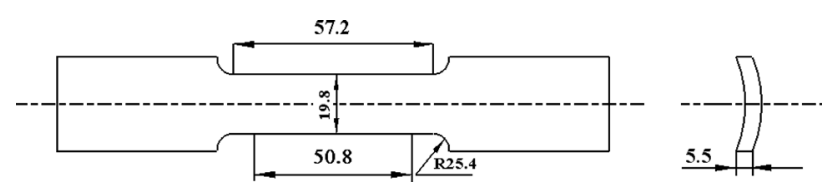

Fig. 2. Schematic diagram of tensile specimen

and mechanical properties varied a lot.

Tensile tests were carried out using specimens having a reduced cross-section of $19.8 \mathrm{~mm} \times 5.5 \mathrm{~mm}$ and a gauge length of $50.8 \mathrm{~mm}$ as shown in Fig. 2, which were machined from the non-boronized and boronized pipes, respectively. The area of the specimen is proposed as $100 \mathrm{~mm}^{2}$ by API Spec 5CT according to its width and thickness. A pair of fasteners with concaves matching the transition edges of the tensile specimen perfectly was used to chuck the tensile specimen, considering the round plate shape of the tensile specimens, thus the tensile tests can be performed smoothly.

Wear testing was conducted with a pin-on-disc type machine under dry sliding condition at a room temperature of 
$298 \mathrm{~K}$ using specimens of $5 \mathrm{~mm}$ diameter $\times 12 \mathrm{~mm}$ length, machined from pipe wall and then boronized separately at $1133 \mathrm{~K}$ for $5 \mathrm{~h}$ and cooled in center of boriding agent within the annealing pipe. The tests were carried out in a load range of $50-150 \mathrm{~N}$ at a sliding speed of $0.785 \mathrm{~m} \mathrm{~s}^{-1}$. Specimens were weighed on a single pan electrical balance that gave readings to an accuracy of $0.1 \mathrm{mg}$, before and after the wear test. The difference in weight of three test pins before and after the experiment gave the average weight loss from a sliding distance of $754.56 \mathrm{~m}$, from which the average wear rate was calculated. The disc was $70 \mathrm{~mm}$ in diameter and made of high carbon chromium steel hardened to a hardness of $57 \mathrm{HRC}$, the surface of which was ground to a constant surface finish of about $0.4 \mu \mathrm{m} \mathrm{Ra}$.

Rectangular specimens of dimensions $10.7 \times 9.6 \times 4.3$ $\mathrm{mm}^{3}$ were used in corrosion immersion tests in acid environments of $\mathrm{HCl} 5 \mathrm{vol} \%$ and $\mathrm{H}_{2} \mathrm{SO}_{4} 5 \mathrm{vol} \%$. At specific time intervals the boronized and non-boronized specimens were withdrawn from the solutions and weighed without any additional treatment like rinsing. Thus, the weight loss was continuously recorded. The immersion tests were repeated three times and mean values were used for the acquisition of weight loss curves. To further evaluate the corrosion resistance and possible passivation behavior of the samples, electrochemical measurements were performed on an Electrochemical Analyzer (LK98C, Tianjin, China). Linear sweep voltammetry experiments were carried out in the aforementioned acid solutions using a classical three-electrode cell with a platinum plate $(\mathrm{Pt})$ as a counter electrode and an $\mathrm{Ag} / \mathrm{AgCl}$ electrode as a reference electrode at room temperature. The working electrode was cleaned in acetone ultrasonically, rinsed in deionized water before the test. The samples were masked with lacquer so that only $1 \mathrm{~cm}^{2}$ area was exposed to the electrolyte. Samples were also degreased with acetone, rinsed in deionized water before the electrochemical test. During the potentiodynamic sweep experiments, the samples were first immersed into electrolyte for about $10 \mathrm{~min}$ to stabilize the open-circuit potential (OCP) E0. The recorded data was transformed to the Tafel plot and the corrosion current density (icorr) was determined by extrapolating the straight-line section of the anodic and cathodic Tafel lines. The sweeping rate was $50 \mathrm{mV} \mathrm{min}^{-1}$ for all the measurements.

\section{Results and Discussion}

\subsection{Microstructure and Hardness of Boride Layer}

Optical microscopy of cross-section of boronized inner surfaces of N80 steel pipes cooled by different cooling methods revealed the formation of a dual-phase boride layer with the thickness ranged from $50 \pm 5$ to $70 \pm 5 \mu \mathrm{m}$ in a sequence of cooling velocity from the fast to the slow, namely graphite-bar assisted rapid cooling, fan cooling, normalizing (air cooling), and annealing (furnace cooling). Figure 3 shows that a dual-phase boride layer of about 64-72 $\mu \mathrm{m}$ thickness was formed on the substrate of the N80 steel pipe subjected to annealing, which was confirmed by X-ray diffraction analysis as illustrated in Fig. 4. The outmost layer was FeB phase of $4-8 \mu \mathrm{m}$ in thickness, which was incompact with some pores and cracks, next to which

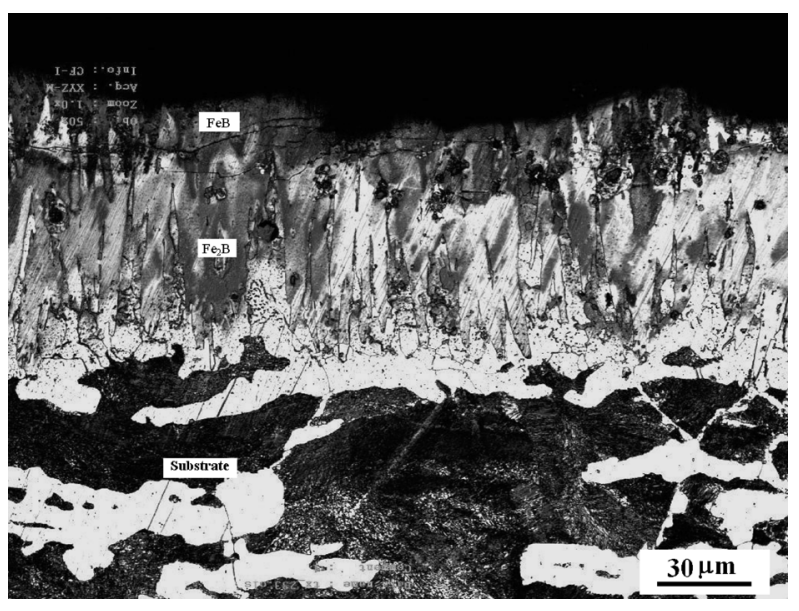

Fig. 3. Optical microscopy cross-sectional view of boronized N80 steel pipe subjected to annealing.

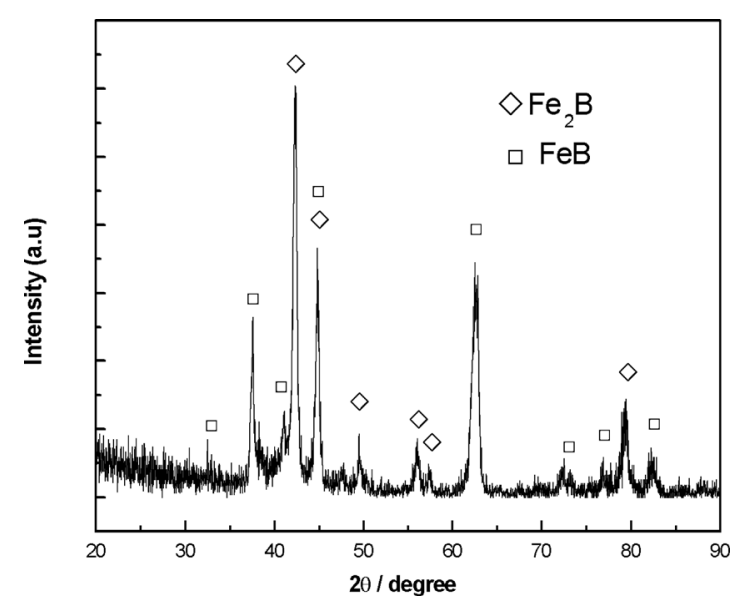

Fig. 4. XRD pattern of boronized N80 steel.

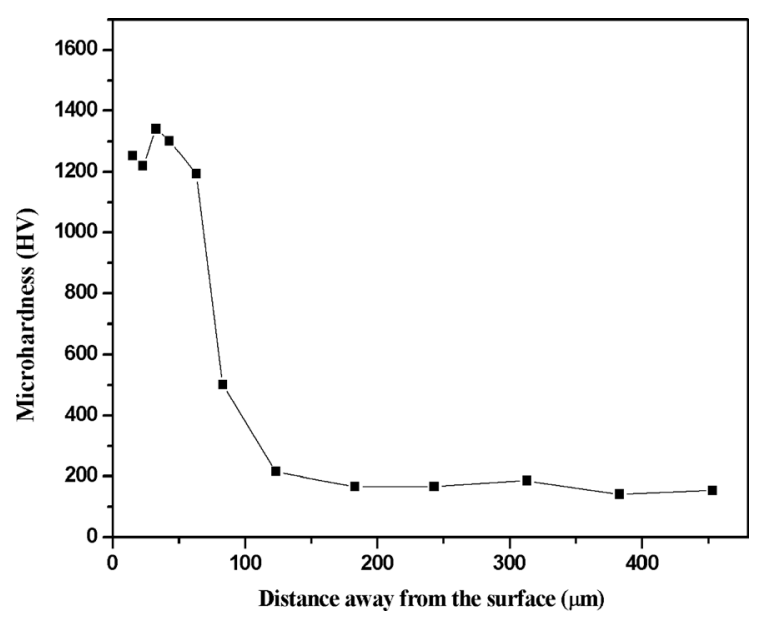

Fig. 5. Hardness profile of boronized N80 steel subjected to annealing.

was a rather thick $\mathrm{Fe}_{2} \mathrm{~B}$ phase layer of about $64 \mu \mathrm{m}$ thickness with a saw-tooth morphology on the steel substrate. This form of the layer makes the layer interlock with the substrate. Thus, the removal of the saw-tooth shaped $F_{2} B$ boride layer by mechanical effects becomes very difficult. ${ }^{4}$ )

Figure 5 shows microhardness profile measured on the same cross-section as shown in Fig. 3. The hardness of the boride layer is about $1220-1340 \mathrm{HV}$, much higher than that 


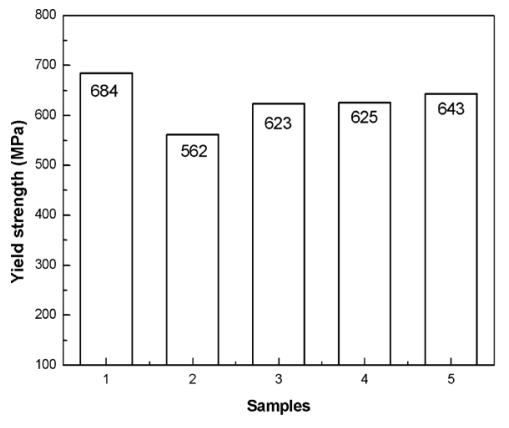

(a)

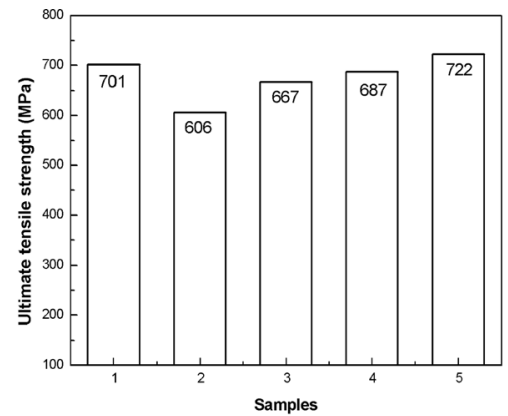

(b)

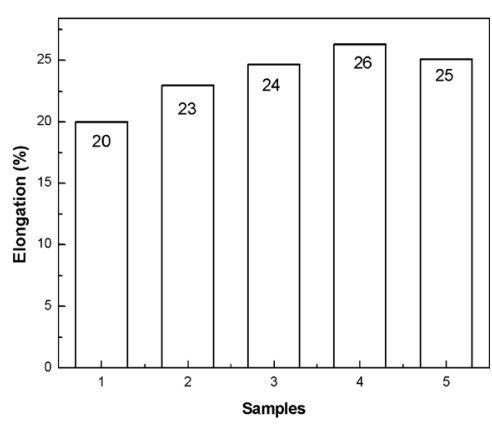

(c)

Fig. 6. Tensile properties of non-boronized and boronized N80 steel pipes: 1. non-boronized, 2. annealing, 3. normalizing, 4. fan cooling, 5. graphite-bar assisted rapid cooling. (a) Yield strength, (b) UTS and (c) elongation.

of the steel substrate $160 \mathrm{HV}$. Because the FeB layer is so thin that this hardness is intrinsic to $\mathrm{Fe}_{2} \mathrm{~B}$ layer. The $\mathrm{Fe}_{2} \mathrm{~B}$ is especially desirable for industrial applications owing to the small difference in the specific volume and coefficient of thermal expansion between the boride and the substrate. $^{12,13)}$

\subsection{Tensile Properties of Boronized N80 Pipes}

The lower limits of mechanical properties of N80 tube required by the API SPEC 5L are as follows:

(1) YS (yield strength) higher than $552 \mathrm{MPa}$;

(2) UTS (ultimate tensile strength) higher than $689 \mathrm{MPa}$;

(3) EL (elongation) higher than 14\%.

To meet these mechanical properties, four cooling methods were tried to obtain different cooling velocities in a sequence of from the slow to the fast, namely annealing, normalizing; fan-cooling and graphite-bar assisted rapid cooling. Two characteristics can be drawn from the tensile properties of boronized and non-boronized N80 steels as shown in Fig. 6: firstly, the boride layer, to a certain extent, deteriorates the tensile properties of the N80 steel tube since most of the tensile properties of boronized pipes are lower than the original one except elongation. Secondly, the cooling velocity can considerably influence the tensile properties, especially YS and UTS. The deterioration of tensile properties is due to the initial fracture of the boride layer in tensile testing process. The common phenomenon was observed for all boronized samples during tensile testing, where at about a tensile force of $52.16 \mathrm{kN}$ which corresponds to a stress of $479 \mathrm{MPa}$, the boride layer began to crack due to its fragile nature, consequently a saw-tooth plateau occurred in the load-elongation curve. Scanning electron microscopy of surface of the sample revealed that the cracks penetrated through the boride layer (see Fig. 7(a)), which might cause stress concentration and tensile properties hence were deteriorated. However, the negative influence of the cracked boride layer is limited because no evidence of brittle fracture like cleavage plane but ductile fracture with dimples is observed in steel substrate nearby the boride layer (see Fig. 7(b)). Figures 8(a) and 8(b) show two typical fracture surface morphologies of the tensile specimens of N80 steel pipes cooled differently. It is noticeable that there is small difference in the fracture mode for N80 steel pipes cooled differently, and all the specimens failed in a ductile fracture with numerous dimples over the fracture surfaces and some carbide particles can be clearly

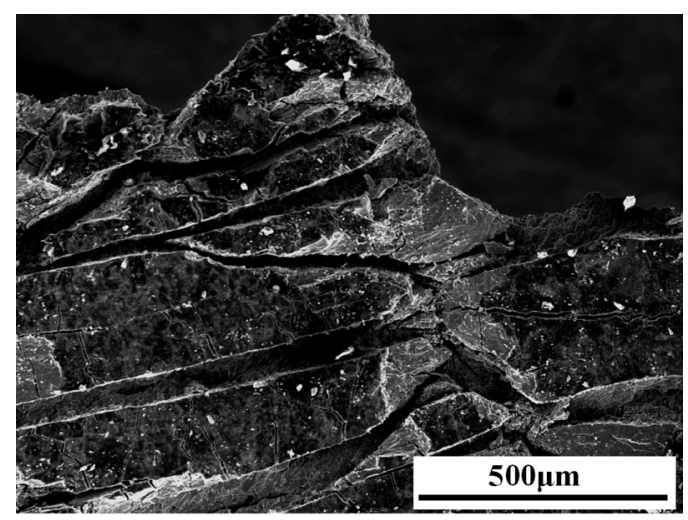

(a)

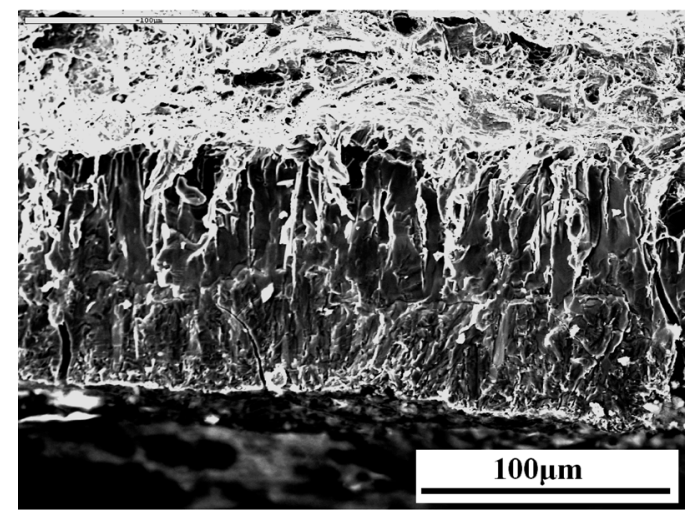

(b)

Fig. 7. SEM micrographs of the cracks nearby the fractured position (a) and fracture surface of the boride layer (b).

observed in the larger dimples, suggesting no change in fracture mode was caused by boride layer.

As the cooling velocity is increased, the yield strength and the ultimate tensile strength are remarkably improved. Since the boride layer does not differ from each other very much in terms of hardness and thickness under four given cooling conditions, and its thickness is so thin as compared with the wall thickness of steel substrate, the tensile properties of boronized N80 steel pipes, to a great extent, are reliant on the properties of steel substrates subjected to the different cooling methods. The comparison of microstructures of steel substrates under four cooling conditions is given in Fig. 9. It can be seen that microstructures of the steel substrates equally consist of lightly-imagery ferrite 
and darkly-imagery pearlite in four cases, but the differences in volume fraction and the grain size for both ferrite and pearlite are rather distinct. As the cooling velocity was

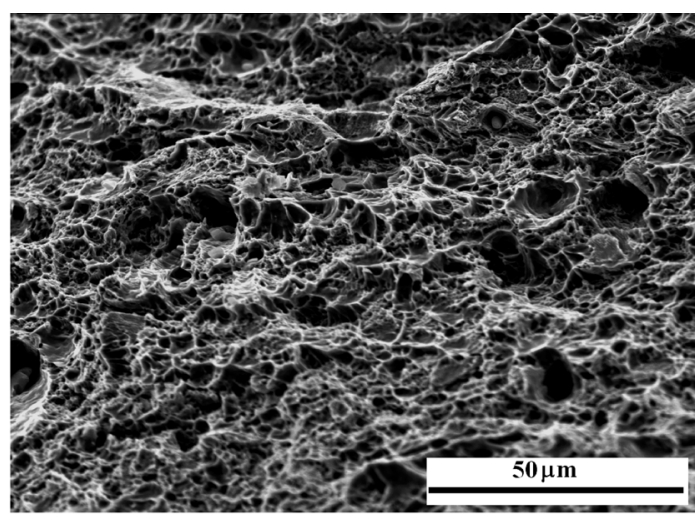

(a)

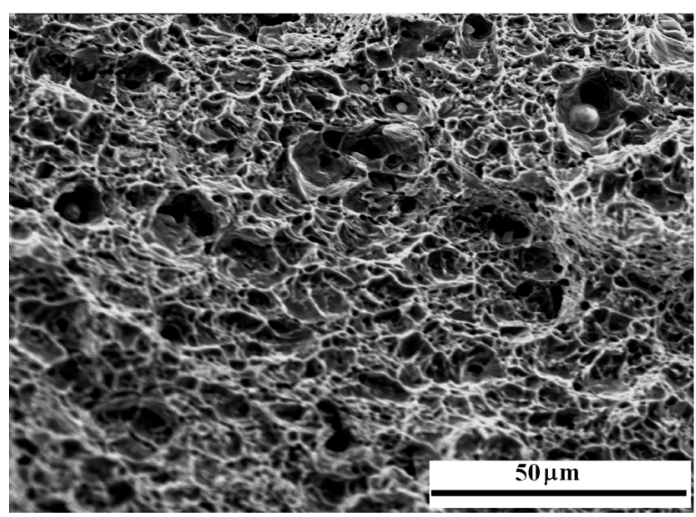

(b)

Fig. 8. Fractured surfaces of tested samples: (a) annealing and (b) graphite-bar assisted rapid cooling.

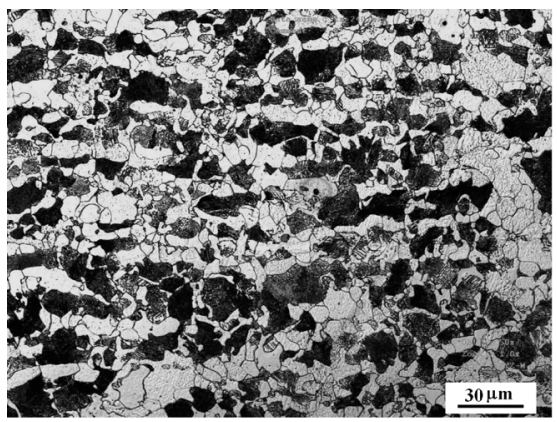

(a)

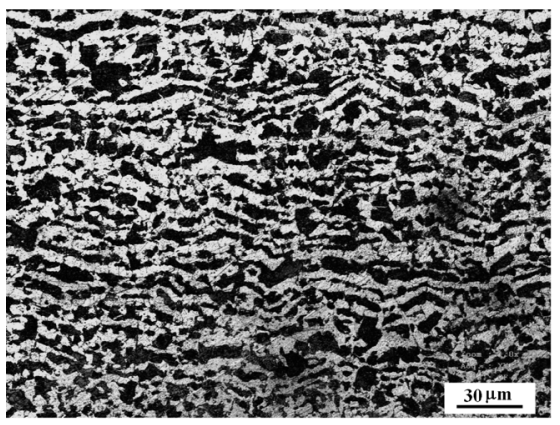

(c) increased from the annealing to the graphite-bar assisted rapid cooling, the volume of pearlite consequently increased from 45.5 to $66.1 \%$, whereas the volume of ferrite was accordingly decreased, and the grain size decreased from 9.3 to $4.2 \mu \mathrm{m}$ for ferrite and from 10.9 to $5.0 \mu \mathrm{m}$ for pearlite, respectively. Though the difference of the grain size of ferrite and pearlite seems large about two times with increasing cooling velocity, the yield strength $\sigma_{y}$ varies with grain size according to the Hall-petch equation:

$$
\sigma_{y}=\sigma_{0}+k_{y} d^{-1 / 2}
$$

where $d$ is the average grain diameter, and $\sigma_{0}$ and $k_{y}$ are constants. The value of $d^{-1 / 2}$ varies little with increasing cooling velocity, therefore, the grain refining effect on the tensile strength was considered to be less than the effect of the increase in pearlite volume. On the basis of the microstructure constituent law of mixture, the yield strength $\left(\sigma_{y}\right)$ of a mixture of ferrite and pearlite can be expressed in terms of volume fraction of ferrite $\left(V_{f}\right)$ and pearlite $\left(V_{p}\right)$ and yield strength of ferrite $\left(\sigma_{f}\right)$ and pearlite $\left(\sigma_{p}\right)$ as follows:

$$
\sigma_{y}=V_{f} \sigma_{f}+V_{p} \sigma_{p}
$$

The pearlite has much higher strength than the ferrite; therefore, increasing the volume of peralite greatly enhances the tensile strength. The theoretical yield strength calculated by Eq. (2) was compared with the measured ones in Table 2, the yield strength for ferrite containing 2\% Mn and pearlite used in Eq. (2) was $260 \mathrm{MPa}$ and $890 \mathrm{MPa}$, respectively. It is found that the effect of variation in pearlite volume on tensile yield strength with cooling velocity is well explained, even though there are large deviations between the calculated and measured results. The main reason that the measured yield strength was lower than the theoretical yield strength in the graphite-bar assisted rapid cooling

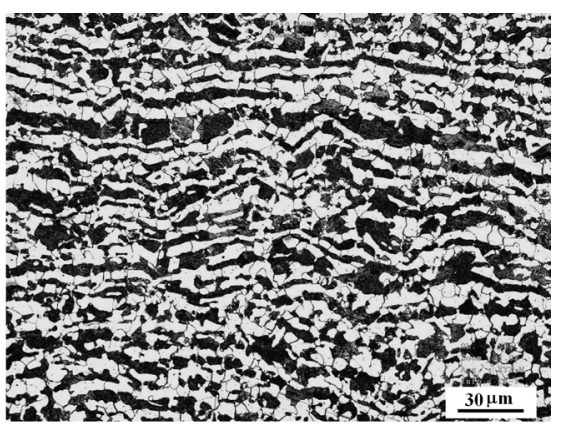

(b)

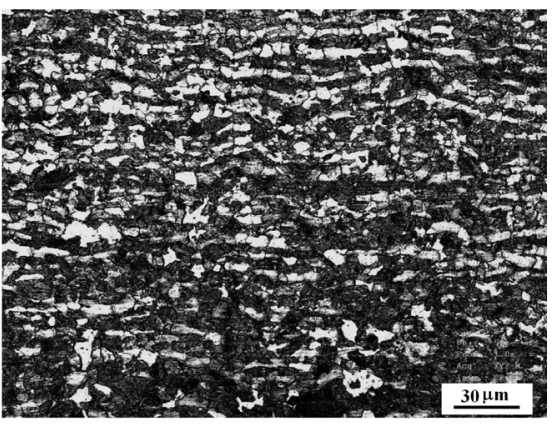

(d)

Fig. 9. Microstructures of N80 steel substrate treated with different methods: (a) annealing, (b) normalizing, (c) fan cooling and (d) graphite-bar assisted rapid cooling. 
Table 2. Microconstituent and yield strength for boronized steels cooled by different methods.

\begin{tabular}{|c|c|c|c|c|c|c|}
\hline $\begin{array}{l}\text { Cooled } \\
\text { method }\end{array}$ & $\begin{array}{l}\text { Pearlite } \\
\text { volume } \\
(\%)\end{array}$ & $\begin{array}{l}\text { Perlite } \\
\text { size } \\
(\mu \mathrm{m})\end{array}$ & $\begin{array}{l}\text { Ferrite } \\
\text { volume } \\
(\%)\end{array}$ & $\begin{array}{l}\text { Ferrite } \\
\text { size } \\
(\mu \mathrm{m})\end{array}$ & $\begin{array}{l}\text { Theoretical } \\
\text { yield } \\
\text { strength } \\
(\mathrm{MPa})\end{array}$ & $\begin{array}{l}\text { Measured } \\
\text { yield } \\
\text { strength } \\
(\mathrm{MPa})\end{array}$ \\
\hline Annealing & 45.5 & 10.9 & 54.5 & 9.3 & 547 & 562 \\
\hline Normalizing & 48.8 & 7.3 & 51.2 & 6.8 & 596 & 619 \\
\hline Fan cooling & 53.1 & 5.6 & 46.9 & 5.5 & 618 & 626 \\
\hline $\begin{array}{l}\text { Graphite-bar } \\
\text { assisted rapid } \\
\text { cooling }\end{array}$ & 66.1 & 5.0 & 33.9 & 4.2 & 676 & 644 \\
\hline
\end{tabular}

is due to the neglect of the increase in yield strength for pearlite with increasing cooling velocity. In the case of YS, all the four kinds of pipes exceeded $552 \mathrm{MPa}$ required by API SPEC 5L, whereas only the graphite-bar assisted rapid cooling tube surpassed $689 \mathrm{MPa}$ of UTS required by API SPEC 5L. All the four kinds of tube exhibited good elongation higher than $20 \%$. Therefore the graphite-bar assisted rapid cooling is the best choice suitable for boronizing N80 tube.

The initial fracture of the boride layer can cause its protection against wear and corrosion lost, but this does not mean that the boronized tube has a great limitation in practical application in oil industry, for the boride layer cracking stress level of $479 \mathrm{MPa}$ can bear a total weight of 43.2 tons of oil pipes, which can reach a $4000 \mathrm{~m}$ depth under oil well and this depth is enough for the conventional oil well.

\subsection{Wear Tests}

The coefficient of friction and wear rate as a function of applied load are shown in Figs. 10(a) and 10(b). The coefficient of friction for both materials decreases with increasing the applied load, and boronized steel exhibits lower value than the non-boronized one though there is not too much difference between them. Friction coefficient ranges from 0.45 to 0.63 for the boronized, and $0.49-0.70$ for the non-boronized N80 steels, respectively. It is evident that the friction coefficient depends systematically on applied load. However, as the load was increased to $150 \mathrm{~N}$, the sudden rise in friction coefficient was observed for the boronized N80 steel and this is due to localized spalling of the boride layer on worn surface, which could be confirmed in the observation of the worn surface. The boronized samples exhibited effective wear resistance compared with the untreated ones. The wear rate of non-boronized steel dramatically rose as applied load exceeded $100 \mathrm{~N}$ because of surface softening caused by substantial friction heat, whereas the boronized steel maintained a low and steady wear process under given conditions due to the presence of boride layer. The boride layer can remain almost intact under rather high load; this can be confirmed from SEM examination of worn surfaces. It was seen that after sliding a distance of $754.56 \mathrm{~m}$, as the load was at $130 \mathrm{~N}$, the boride layer remained almost intact except a few grooves on the worn surface as shown in Fig. 11(a), indicating an abrasive wear mechanism. Previous studies by Hungar and Trute have shown that the boronized steels are extremely resistant to abrasion and adhesion on account of their great hardness and the boride layers have low welding tendency. ${ }^{14)}$ This

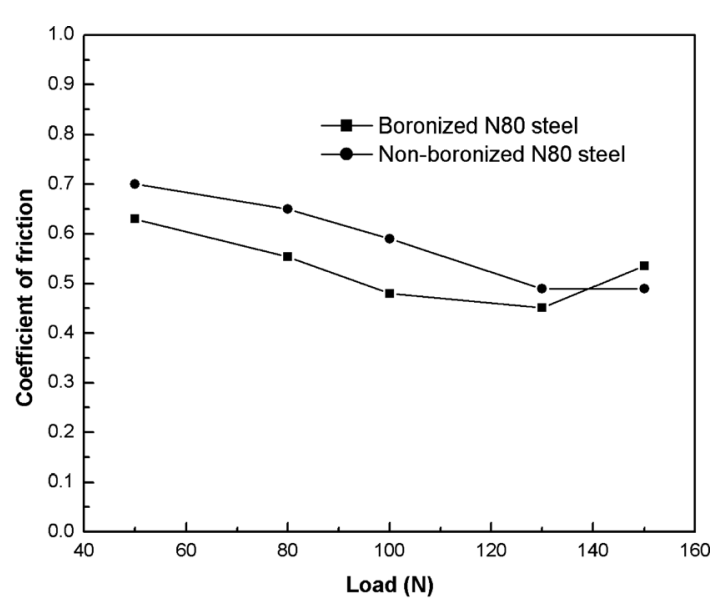

(a)

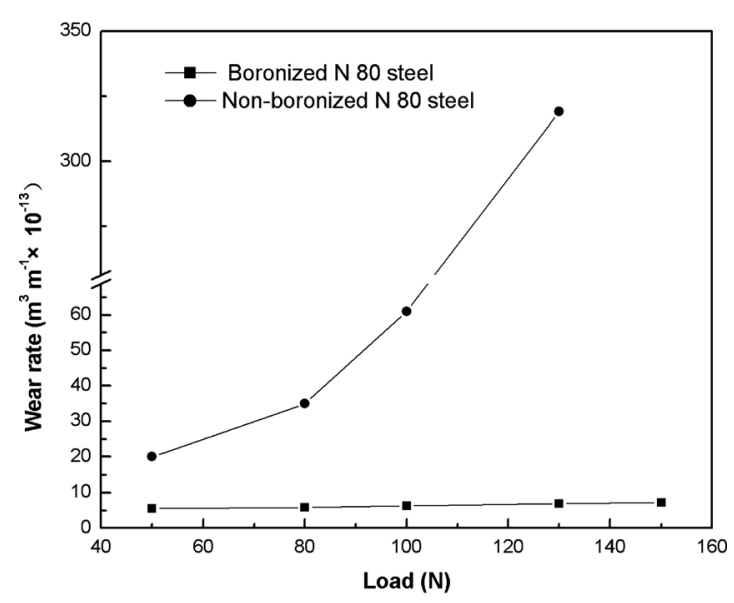

(b)

Fig. 10. The variation in coefficient of friction (a) and wear rate (b) for non-boronized and boronized N80 steels subjected to annealing.

property is of great consequence for adhesive wear and explain why boronized samples show higher wear resistance. As the load was increased up to $150 \mathrm{~N}$ (see Fig. 11(b)), boride layer still covered most of the worn surface though a few cracks occurred at localized area. Once the boride layers cracked and flaked off on a large scale under heavy load, the protection of boride layer, restricting metal-to-metal contact between pin and disc, would lose, consequently the wear rate is expected to increase much faster.

\subsection{Corrosion Tests}

The corrosion resistance of the boride layer was investigated by polarization curves and acid immersion tests. Figure 12 shows electrochemical polarization curves for the non-boronized and boronized N80 steels in $\mathrm{HCl}$ and $\mathrm{H}_{2} \mathrm{SO}_{4}$ solutions, respectively, at room temperature. The corrosion potentials for the non-boronized and boronised N80 steel are summarized in Table 3. In both solutions, corrosion potentials $E_{\text {cor }}$ of boronized N80 steel are more electropositive than those of the non-boronized N80 steel. This means that boride layer can act as a protection barrier for the N80 steel under this specific corrosion environments. The above was verified by the immersion test results (Fig. 13) where the boride layer substantially reduced the weight loss in both $\mathrm{H}_{2} \mathrm{SO}_{4}$ and $\mathrm{HCl}$ solutions. Comparison of the samples ap- 


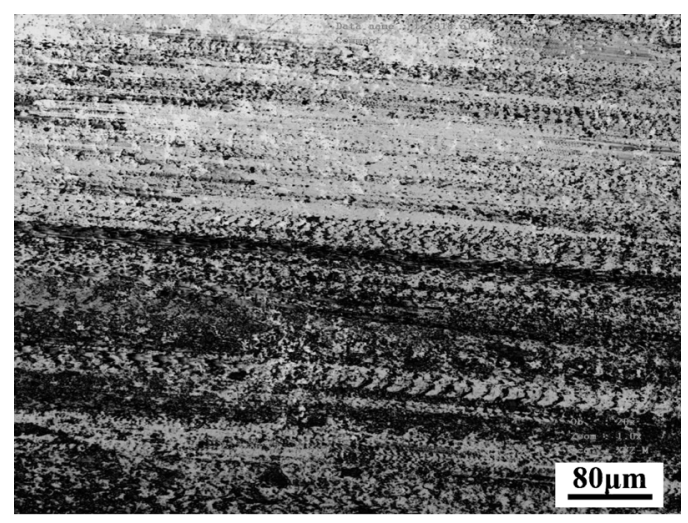

(a)

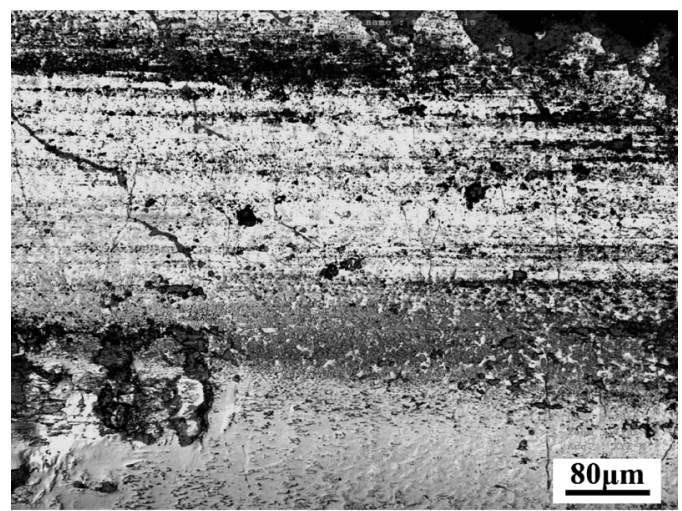

(b)

Fig. 11. Worn surface morphology of boronized N80 steel subjected to annealing at different applied load: (a) $130 \mathrm{~N}$ and (b) $150 \mathrm{~N}$, showing localized cracks on the worn surface.

Table 3. Corrosion potential values $E_{\text {cor }}$ of the plain and boronized $\mathrm{N} 80$ steel in $\mathrm{HCl}$ and $\mathrm{H}_{2} \mathrm{SO}_{4}$ solutions.

\begin{tabular}{lll}
\hline Solutions & Non-boronized N80 & Boronized N80 \\
\hline $\mathrm{HCl} 5 \mathrm{Vol} \% \%$ & $-534 \mathrm{mV}$ & $-458 \mathrm{mV}$ \\
$\mathrm{H}_{2} \mathrm{SO}_{4} 5$ vol.\% & $-532 \mathrm{mV}$ & $-475 \mathrm{mV}$ \\
\hline
\end{tabular}

pearance after immersion test gave a stronger impression that more than half of the plain sample has corroded after immersion for $100 \mathrm{~h}$ in $\mathrm{H}_{2} \mathrm{SO}_{4}$ solution (not shown here). This result is similar to the report on corrosion behaviour of boronized AISI $\mathrm{H} 13$ hot work steels in $\mathrm{H}_{2} \mathrm{SO}_{4}$ and $\mathrm{HCl}$ solutions provided by Kariofillis et al., ${ }^{10)}$ in which corrosion potentials $E_{\text {cor }}$ in the boronized AISI H13 steels were more electropositive than those of the plain steels.

\section{Conclusions}

(1) Duplex boride layers in a thickness range from $50 \pm 5$ to $70 \pm 5 \mu \mathrm{m}$ were formed on N80 steel substrate at $860^{\circ} \mathrm{C}$ for $5 \mathrm{~h}$ by pack boronizing, which consisted of a thin outer layer of $\mathrm{FeB}$ phase and a rather thick layer of $\mathrm{Fe}_{2} \mathrm{~B}$ phase with a saw-tooth morphology, with a hardness range of $1220-1340 \mathrm{HV}$.

(2) The interior design of the boronizing set-up in conjunction with different cooling methods can significantly

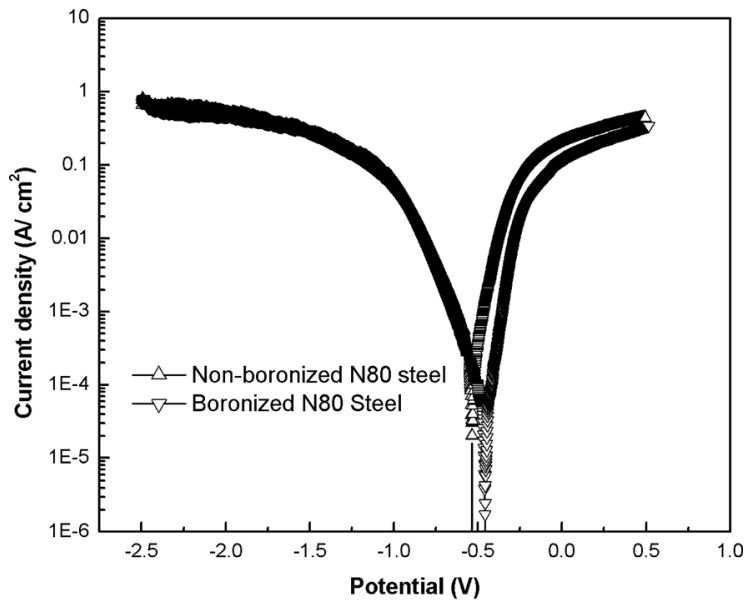

(a)

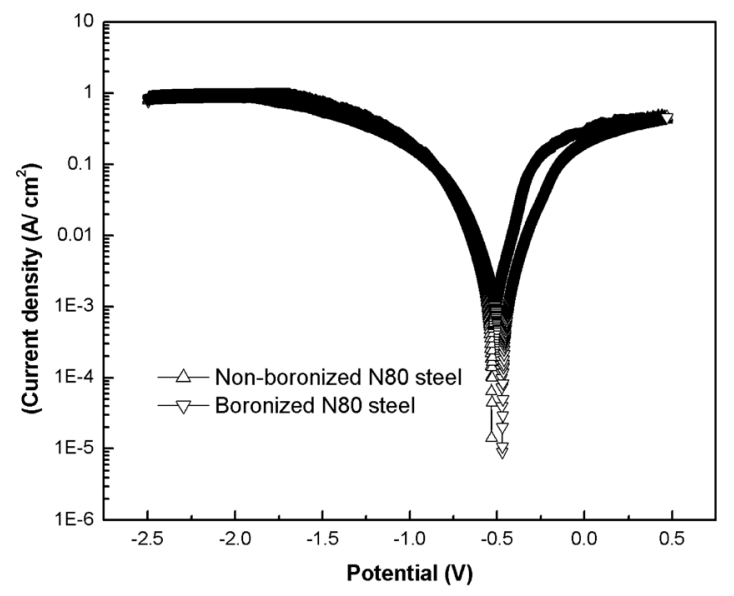

(b)

Fig. 12. Potentiodynamic polarization curves of the nonboronized and boronized N80 steel in acid solutions: (a) $\mathrm{HCl} 5 \mathrm{vol} \%$ and (b) $\mathrm{H}_{2} \mathrm{SO}_{4} 5 \mathrm{vol} \%$.

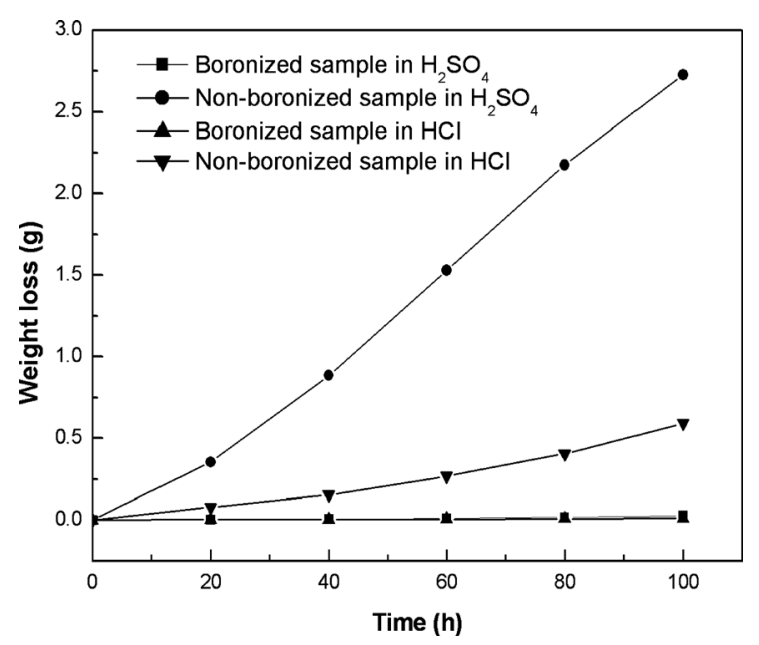

Fig. 13. Weight loss of immersion tests of the non-boronised and boronized $\mathrm{N} 80$ steel in $\mathrm{HCl} 5 \mathrm{vol} \%$ and $\mathrm{H}_{2} \mathrm{SO}_{4} 5 \mathrm{vol} \%$ solutions.

influence both the microstructure and mechanical properties of boronized N80 steel pipes, the finest microstructure consisted of ferrite and the highest fraction of pearlite has been obtained by graphite-bar assisted rapid cooling, and its mechanical properties meet the API SPEC 5L standard.

(3) The boride layer provides excellent wear resistance 
in a load range of $50-130 \mathrm{~N}$ at a sliding speed of $0.785 \mathrm{~m} \mathrm{~s}^{-1}$ and improves corrosion resistance of the N80 steel in $\mathrm{H}_{2} \mathrm{SO}_{4} 5 \mathrm{vol} \%$ and $\mathrm{HCl} 5$ vol\% solutions.

\section{Acknowledgements}

The authors thank the Project 985-automotive engineering of Jilin University and Technology Development Program of Jilin Province (No. 20080314).

\section{REFERENCES}

1) A. K. Sinha: Boronising, ASM Handbook, OH, USA, J. Heat Treat., 4 (1991), 437.

2) P. Goeuriout, F. Thevenot, J. Thevenot and H. Driver: Thin Solid Films, 78 (1981), 67.

3) U. Sen, S. Sen and F. Yilmaz: J. Mater. Process. Technol., 148 (2004), 1.
4) B. Selcuk, R. Ipek and M. B. Karamis: J. Mater. Process. Technol., 141 (2003), 189.

5) S. G. Laskshmi and D. Arivuli: Tribol. Int., 37 (2004), 627.

6) P. Asthana, H. Liang, M. Usta and A. H. Ucisik: J. Tribol., 129 (2007), 1.

7) O. I. Radkevych, H. V. Chumalo, I. M. Dominyuk and I. I. Vasylenko: Mater. Sci., 38 (2002), 884.

8) V. V. Zavyalov and L. S. Moiseeva: Chemical and Petroleum Engineering, 40 (2004), 45.

9) C. Martini, G. Palombarini, G. Poli and D. Prandstraller: Wear, 256 (2004), 608

10) G. K. Kariofillis, G. E. Kiourtsidis and D. N. Tsipas: Surf. Coat. Technol., 201 (2006), 19.

11) V. Jain and G. Sundararajan: Surf. Coat. Technol., 149 (2002), 21.

12) C. Bindal and A. Erdemit: Appl. Phys. Lett., 86 (1996), 923.

13) Y. Pengxun: Thin Solid Film, 214 (1992), 44.

14) H. J. Hungar and G. Trute: Heat Treament Met., 2 (1994), 31. 